\title{
Optimization of Fermentation Medium for the Production of Recombinant Human Antithrombin III from Saccharomyces cerevisiae through Statistical Experimental Designs
}

\author{
Maheswara Reddy Mallu, Sandeep Vemula, Srinivasa Reddy Ronda* \\ KLE F University, Centre for Bioprocess Technology, Department of Biotechnology, Guntur-522 502, Andhra Pradesh, India.
}

\begin{tabular}{l} 
ARTICLE INFO \\
\hline Article history: \\
Received on: 05/10/2015 \\
Revised on: 23/10/2015 \\
Accepted on: 08/11/2015 \\
Available online: 27/12/2015 \\
\hline Key words: \\
Optimization; Placket- \\
Barman design; Central \\
composite design; \\
Antithrombin; \\
Saccharomyces cerevisiae.
\end{tabular}

\begin{abstract}
This work, for the first time reports the optimization of recombinant human antithrombin (rhAT) production in Saccharomyces cerevisiae BY4741 using statistical experimental designs. Most applications of design of experiments (DoE) have concerned optimization of the composition of growth and production culture media. The typical objective is to identify a best selection and quantitative composition of significant medium supplements. In the present study, Plackett-Burman (PB) design followed by central composite design has been employed to evaluate and optimize the suitable culture medium for rhAT production. Influence of raffinose, glutamic acid and vitamin mixture were screened to be significant variables by PB design. The significant nutritional variables were further optimized using central composite design (CCD) for maximum production of rhAT. Central composite design (CCD) has been selected to explain the interaction effect of the three significant variables such as raffinose, glutamic acid, and vitamin mixture. The multiple regression equation $\left(R^{2}=0.9967\right)$ was used to optimize significant impact of medium component values to maximize rhAT formation. The optimized values were found to be $23.09765 \mathrm{~g} / \mathrm{L}, 8.01816 \mathrm{~g} / \mathrm{L}$ and $77.2056 \mathrm{mg} / \mathrm{L}$ for raffinose, glutamic acid and vitamin mixture, respectively. The maximum yield of rhAT of $38.97 \mu \mathrm{g} / \mathrm{mL}$ was obtained experimentally using CCD and was very close to the predicted response of $38.93 \mu \mathrm{g} / \mathrm{mL}$.
\end{abstract}

\section{INTRODUCTION}

Antithrombin is a glycolprotein having 432 amino acid residues, 4 glucosamine-based oligosaccharide side units, and 3 disulfide bridges (Franzen et al., 1980 and Petersen et al., 1979). It is produced in the liver and has a plasma level of approximately $150 \mathrm{mg} / \mathrm{L}$ (Murano et al., 1980). Recombinant human antithrombin (rhAT) is the most significant inhibitor of thrombin family and activated factor X (FXa). Although, antithrombin acts mainly as the most significant plasma inhibitor of thrombin and antithrombin has also strong inhibitory effects on variety of active serine proteases, including IXa, Xa, Xia, XIIa, and FVIIa factors (Damus et al., 1973 and Travis et al., 1983). This is demonstrated by the fact that individuals with

* Corresponding Author

Srinivasa Reddy Ronda, K L E F University, Centre for Bioprocess Technology, Department of Biotechnology, Guntur-522 502, Andhra Pradesh, India.Email: rsr@kluniversity.in antithrombin deficiency are predisposed to thrombotic events and difficiency of antithrombin is a hereditary disorder that is connected with recurrent thrombophlebitis, aortic thromiosis and thromo embolism (Egeberg 1965). Besides being involved in regulating coagulation, antithrombin has been shown to have anti inflammatory properties (Wiedermann et al., 2002). rhAT is useful to cure diseases such as Transient Ischemic Attack, Thrombosis, Thrombocytosis and Cerebrovascular diseases are the main causes of death and disability around the globe (De Stefano et al., 2008). Because of these properties, antithrombin is useful as a therapeutic agent to treat diseases and hence rich source of extremely purified and active rhAT might be supportive for clinical and model validation studies (Linhardt et al., 2003). rhAT is achieving increasing attention due to their possible use in clinical and model validation studies.

The use of recombinent proteins at a commercial scale is constrained by the ability to gain the product in higher yields from microbial processes (Freigassner et al., 2009). 
The growing demand for therapeutic products calls for robust production hosts, capable expression systems and appropriate cultivation conditions. The limitation is often in terms of obtaining upmost quantities at sufficiently low cost to allow for marketing. Yeast is a single-celled, eukaryotic microbe that can grow speedily in complex or defined media (doubling time is typically $2.5 \mathrm{~h}$ in glucose-containing medium) and is simple and economical to use for r-DNA based protein production than insect and other mammalian cell lines (Bill 2001). The main advantage of yeast expression systems is the capacity to perform strict quality control and post-translational modifications (Demain et al., 2009).

To achieve high product yields, media composition is one of the important parameter. The optimal culture medium depends on many factors, including host metabolism, potential inhibitory products, target proteins, etc, and the development of the optimal medium is often a trial and error process (Shojaosadati et al., 2008). On one hand, it is desirable from the cost perspective to make the medium as simple as possible by reducing the amount of non essential carbon and nitrogen sources. It is prerequisite to evaluate and optimize positive impact of medium components in an efficient fermentation process.

Statistical experimental designs are useful tools in bioprocess development to screen out an effective real variable with significance impact (Weuster-Botz, 2000; Mandenius et al., 2008; Box et al., 2005). The application of statistical experimental designs in optimization can give better biomass yields, decreased process variability, closer confirmation of the response to nominal, target requirements, reduced time and overall costs (Brereton et al., 2003).

Usual practice of single factor optimization by maintaining other factors involved an undetermined steady point does not show the pooled effect of all the factors involved (Vaidya et al., 2003).

To make a full factorial search, which would study each possible combination of independent variable at suitable levels could require a big number of experiments and is a time consuming process, which is unreliable. Industrially the aim is to carry out the minimum number of experiments to analyze optimal conditions. These limitations of a single factor optimization process can be removed by $\mathrm{PB}$ design to examine more than five variables (Ahuja et al., 2004), the PB design is used to evaluate the most important variables for the better cell growth and product formation.

The next stage of medium optimization would be to find the optimum level of each effective independent variables which has been recognized by the Placket-Burman design. This may be done by using most popular central composite design (CCD) under response surface methodology (RSM) technique. The CCD is used to optimize the relative significance of several affecting factors even in the presence of complex interactions and to estimate the coefficients of quadratic model (Rao et al., 2000 and Bezerra et al., 2008). In the present study, this communication reports an effort to evaluate and optimize highly effective medium components with significance impact on rhAT production by $\mathrm{P}-\mathrm{B}$ design followed by RSM.

\section{MATERIALS AND METHODS}

\section{Strains and chemicals}

Saccharomyces cerevisiae BY4741 with pYES2/CT expression vector was used as the host for production of rhAT (ATCC 4040002, USA). Yeast nitrogen base (YNB) without uracil, aspartic acid, Raffinose, Galactose, complete supplement mixture and vitamin mix were procured from Himedia, India. Surose, Starch, Fructose, Glutamic acid, Soy peptone, Peptone and ammonium nitrate were procured from Merck (CA, USA). SDS loading dye was purchased from Thermo Scientific, USA and coomassie brilliant blue (CBB-250) and Bovine serum albumin (BSA) were obtained from Bio-Rad Inc, USA.

\section{Culture conditions}

For inoculum development, a single colony of yeast was used to grow the overnight seed culture. For optimization experiments, the seed culture at $10 \%(\mathrm{v} / \mathrm{v})$ was transferred to 100 $\mathrm{mL}$ YNB-URA media containing flasks and incubated for $24 \mathrm{~h}$ at $30{ }^{\circ} \mathrm{C}$. The cultures were induced with galactose $(20 \%)$ and raffinose $(10 \%)$ induction medium.

\section{SDS-PAGE analysis of $\operatorname{rhAT}$}

Equal cell density was maintained by changing the optical density to 1.0 with the growth media and the pellets were collected through centrifugation. To remove the media traces and membrane surface proteins, cells were resuspended in the sterile distilled water. The cell pellets were then collected through centrifugation at $30,000 \mathrm{~g}$ for $15 \mathrm{~min}$ at $4^{\circ} \mathrm{C}$ and stored at $-20^{\circ} \mathrm{C}$ for further analysis.

The cells were treated with SDS loading dye (Thermo Scientific, USA) and lysed with frequent vortexing followed by heating at $100^{\circ} \mathrm{C}$. The samples were directly loaded and resolved with the $12 \%$ acrylamide sodium dodecyl sulphate polyacrylamide gel electrophoresis (SDS-PAGE). The gels were stained with coomassie brilliant blue (CBB-250, Bio-Rad Inc, USA) solution for $8 \mathrm{~h}$.The intensity and rhAT bands were analyzed with ImageJ v1.48 software against the standard protein (Bovine serum albumin, BSA) (Vemula et al., 2015).

\section{Experimental design and optimization}

\section{PB Design analysis for rhAT production}

PB Design was employed for screening the most significant medium components affecting rhAT production by Sacharomyces cerevisiae. In the present study, a 12 run PB Design have been applied to evaluate 11 variables in which two were dummy variables to obtain an estimate of error. Each independent variable was tested at two levels, low and high, which were denoted by (+) and (-) respectively (Table. 1). Table. 2 shows the details of the experimental design and yields of rhAT. 
Table 1: PB design showing the low (-) and high (+) values of the coded nutritional variables.

\begin{tabular}{|c|c|c|c|}
\hline Coded variables & Name of the variables & Low value (-) & High value (+) \\
\hline $\mathrm{A}$ & Raffinose (g/L) & 10 & 20 \\
\hline B & Sucrose $(g / L)$ & 10 & 20 \\
\hline $\mathrm{C}$ & $\operatorname{Starch}(\mathrm{g} / \mathrm{L})$ & 10 & 20 \\
\hline $\mathrm{D}$ & Fructose (g/L) & 10 & 20 \\
\hline $\mathrm{E}$ & Dummy variable-1(g/L) & 5 & 10 \\
\hline $\mathrm{F}$ & Glutamic acid (g/L) & 2 & 8 \\
\hline G & Soy peptone $(\mathrm{g} / \mathrm{L})$ & 2 & 8 \\
\hline $\mathrm{H}$ & Dummy variable-2 (g/L) & 5 & 10 \\
\hline $\mathrm{J}$ & Peptone $(\mathrm{g} / \mathrm{L})$ & 2 & 8 \\
\hline $\mathrm{K}$ & Ammonium nitrate $(\mathrm{g} / \mathrm{L})$ & 2 & 8 \\
\hline $\mathrm{L}$ & Vitamin mixture (mg/L) & 20 & 80 \\
\hline
\end{tabular}

Table 2: PB design for medium optimization and measured response for rhAT yield $(\mu \mathrm{g} / \mathrm{mL})$.

\begin{tabular}{|c|c|c|c|c|c|c|c|c|c|c|c|c|}
\hline \multicolumn{13}{|c|}{ Process variables } \\
\hline Run & $\mathbf{A}$ & $\mathbf{B}$ & $\mathbf{C}$ & D & $\mathbf{E}$ & $\mathbf{F}$ & $\mathbf{G}$ & $\mathbf{H}$ & $\mathbf{J}$ & $\mathbf{K}$ & $\mathbf{L}$ & rhAT yield $(\mu \mathrm{g} / \mathrm{mL})$ \\
\hline 1 & 1 & 1 & -1 & 1 & 1 & 1 & -1 & -1 & -1 & 1 & -1 & 16.3 \\
\hline 2 & -1 & 1 & -1 & 1 & 1 & -1 & 1 & 1 & 1 & -1 & -1 & 11.1 \\
\hline 3 & -1 & -1 & -1 & -1 & -1 & -1 & -1 & -1 & -1 & -1 & -1 & 12.2 \\
\hline 4 & -1 & 1 & 1 & 1 & -1 & -1 & -1 & 1 & -1 & 1 & 1 & 13.1 \\
\hline 5 & -1 & -1 & 1 & -1 & 1 & 1 & -1 & 1 & 1 & 1 & -1 & 14.3 \\
\hline 6 & 1 & 1 & -1 & -1 & -1 & 1 & -1 & 1 & 1 & -1 & 1 & 17.1 \\
\hline 7 & 1 & 1 & 1 & -1 & -1 & -1 & 1 & -1 & 1 & 1 & -1 & 13.2 \\
\hline 8 & -1 & 1 & 1 & -1 & 1 & 1 & 1 & -1 & -1 & -1 & 1 & 16.2 \\
\hline 9 & -1 & -1 & -1 & 1 & -1 & 1 & 1 & -1 & 1 & 1 & 1 & 16.3 \\
\hline 10 & 1 & -1 & -1 & -1 & 1 & -1 & 1 & 1 & -1 & 1 & 1 & 17.5 \\
\hline 11 & 1 & -1 & 1 & 1 & -1 & 1 & 1 & 1 & -1 & -1 & -1 & 16.5 \\
\hline 12 & 1 & -1 & 1 & 1 & 1 & -1 & -1 & -1 & 1 & -1 & 1 & 14.8 \\
\hline
\end{tabular}

Table 3: Coded and uncoded values of central composite design experimental variables.

\begin{tabular}{|c|c|c|c|c|c|c|c|}
\hline \multicolumn{8}{|c|}{ Levels of variables } \\
\hline Variables & Coded variables & -2 & -1 & $\mathbf{0}$ & +1 & +2 & Step change value $\left(\Delta Z_{i}\right)$ \\
\hline Raffinose (g/L) & $\mathrm{A}_{1}$ & 10 & 15 & 20 & 25 & 30 & 5 \\
\hline Glutamic acid (g/L) & $\mathrm{A}_{2}$ & 2 & 4 & 6 & 8 & 10 & 2 \\
\hline Vitamin mix (mg/L) & $\mathrm{A}_{3}$ & 20 & 40 & 60 & 80 & 100 & 20 \\
\hline
\end{tabular}

\section{Response surface Methodology (RSM)}

Response surface methodology is an experimental statistical model employed to explain the nature of response surface in the optimum region. To find out the optimum response of cells and for multiple regression analysis with results obtained from experimental design to solve multivariable equations simultaneously for better yield of rhAT under a broad choice of process variable conditions. A range of coded and un-coded variables was given in Table 3. In this study, a five level and three factors CCD requiring 20 experiments was performed (Table 4). The CCD consists of a $2^{\mathrm{k}}$ factorial runs with $2 \mathrm{k}$ axil runs and $\mathrm{x}_{0}$ number of center points (six replicates). The number of experimental runs was determined from the following equation:

$$
\mathrm{N}=2^{\mathrm{k}}+2 \mathrm{k}+\mathrm{x}_{0}
$$

where $\mathrm{N}$ is the number of experimental runs required, $\mathrm{k}$ is the total

number of nutritional variables and $\mathrm{x}_{0}$ is the total number of central points. Total number of experimental runs were estimated to be $20\left(\mathrm{k}=3\right.$ and $\left.\mathrm{x}_{0}=6\right)$.

The relationships of nutritional variables were evaluated by fitting a second order polynomial equation to information of 20 experiments. The quadratic model was established as follows

$$
\hat{\mathrm{Y}}=\beta_{0}+\sum_{i=1}^{k} \beta_{\mathrm{i}} \mathrm{A}_{\mathrm{i}}+\sum_{i=1}^{k} \beta_{\mathrm{ii}}\left(\mathrm{A}_{\mathrm{i}}\right)^{2}+\sum_{i} \sum_{j} \beta_{\mathrm{ij}} \mathrm{A}_{\mathrm{i}} \mathrm{A}_{\mathrm{j}}
$$

where $\hat{Y}$ is the predicted response (rhAT production) $\beta_{0}$ is a constant, $\beta_{\mathrm{i}}$ linear terms coefficients, $\beta_{\mathrm{ii}}$ quadratic terms coefficient and $\beta_{\mathrm{ij}}$ interaction coefficients. The relationship between coded and uncoded form of the variables is given as follows.

$$
\mathrm{A}_{\mathrm{i}}=\left(\left(\mathrm{Z}_{\mathrm{i}^{-}}\left(\mathrm{Z}_{\mathrm{i}}\right)^{*}\right) / \Delta \mathrm{Z}_{\mathrm{i} / \ldots}(3)\right.
$$

where $A_{i}$ is the coded value of the variable, $Z_{i}$ is the real value of an independent variable (un coded), $\left(\mathrm{Z}_{\mathrm{i}}\right)^{*}$ is the center point value and $\Delta \mathrm{Z}_{\mathrm{i}}$ is the step change between the levels.

\section{RESULTS AND DISCUSSION}

\section{Screening of significant nutritional variables for rhAT Production using PB design}

Statistical design for media optimization has proved to be a powerful and practical tool for bioprocess engineering. An attempt has been made to improve the composition of the medium formulation by simultaneous comparison between two levels of several factors through PB design. In the present work, a study has been performed to analyze the significant effect of various nutritional variables such as raffinose, sucrose, starch, fructose, glutamic acid, ammonium nitrate, peptone, soy peptone and vitamin mix. on rhAT yield. The effects of these components on the rhAT production and maximum rhAT concentration (17.5 $\mu \mathrm{g} / \mathrm{mL}$ ) were shown in Table 2. Fig.1 shows pareto chart of the most important factors determining the rhAT production and response values of raffinose, glutamic acid and vitamin mixture, 


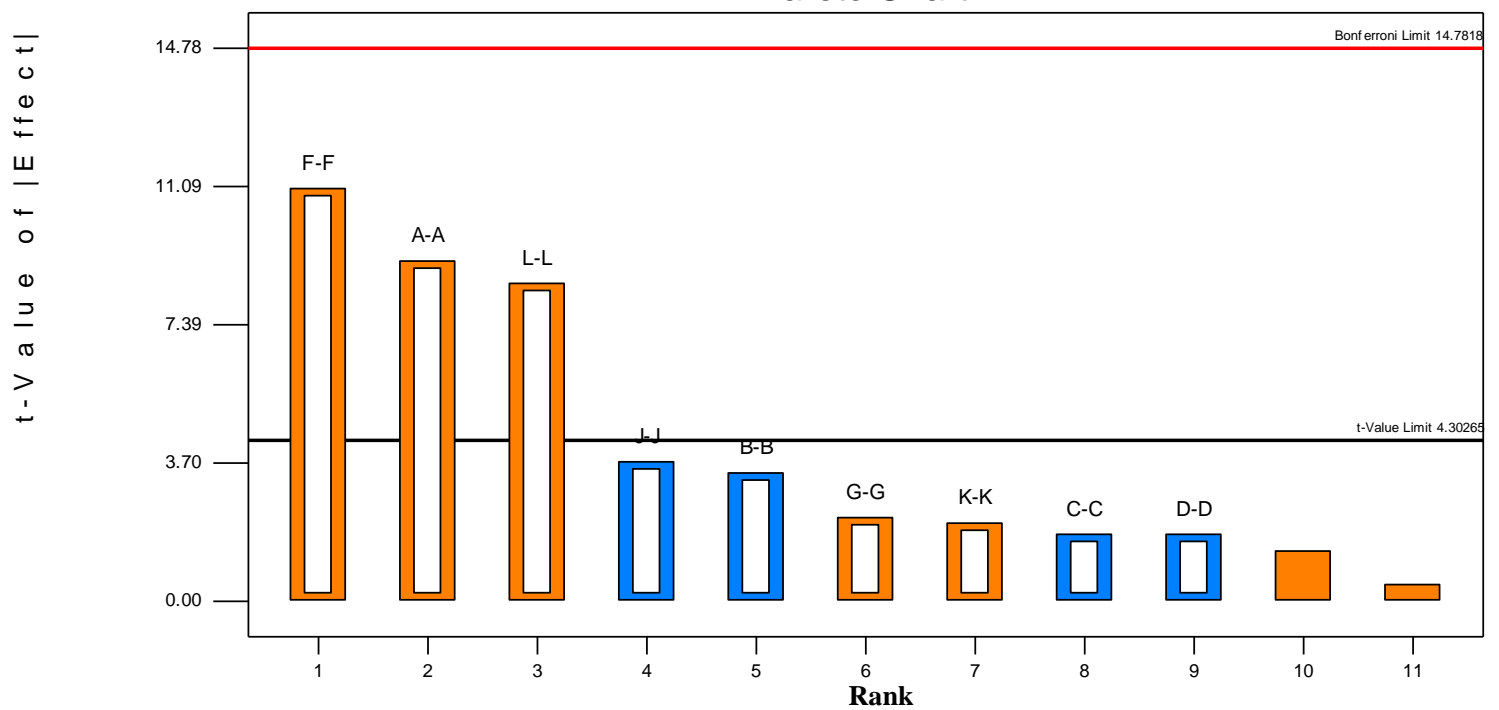

Fig. 1: Effect of medium supplements on rhAT production as shown in pareto chart. $A=$ raffinose, $B=$ sucrose,$C=$ starch, $D=$ fructose, $F=$ glutamic acid, $\mathrm{G}=$ Soy peptone, $\mathrm{J}=$ peptone, $\mathrm{K}=$ Ammonium nitrate and $\mathrm{L}=$ vitamin mixture.

which were above the "Bonferroni limit. From the results, it has been observed that the nutritional variables which show significant effect were considered to have greater effect on rhAT yield.

Table 5 shows Analysis of variance (ANOVA) outcome with significant $F$-value (30.5) and Prob $>$ F value (less than 0.05 ). The goodness of the fit of the model was examined by the multiple correlation coefficient $\left(R^{2}=0.9937\right)$. The adjusted multiple correlation value (adj $\left.R^{2}=0.9656\right)$ is in reasonable correlation with the predicted multiple correlation (pred $R^{2}=0.7750$ ). Adeq Precision investigates the signal to noise ratio, a ratio of 18.102 indicates an adequate signal. The coefficient of variance $(\mathrm{CV}=$ $2.87 \%$ ), which is comparatively low value, indicates a better reliability and precision. A first order model was used to build predictions about the response to the given level of each factor which is defined by the following equation:

$$
\begin{gathered}
\operatorname{rhAT}=14.88+1.02 * \mathrm{~A}-0.38 * \mathrm{~B}-0.2 * \mathrm{C}-0.2 * \mathrm{D}+1.23 * \mathrm{~F}+0.25 * \\
\mathrm{G}-0.42 * \mathrm{~J}-0.23 * \mathrm{~K}+0.95 * \mathrm{~L} \ldots(4)
\end{gathered}
$$

where $\mathrm{A}=$ raffinose, $\mathrm{B}=$ sucrose, $\mathrm{C}=$ starch, $\mathrm{D}=$ fructose, $\mathrm{F}=$ glutamic acid, $\mathrm{G}=$ Soy peptone, $\mathrm{J}=$ peptone, $\mathrm{K}=$ Ammonium nitrate and $\mathrm{L}=$ vitamin mixture. From the results it has been observed that, the rhAT yield was mainly due to three significant factors such as raffinose, glutamic acid and vitamin mixture, which were not reported in previous reports of media optimization. These three significant nutritional variables have shown the potentiality for the biomass and rhAT yield. Of the different carbon sources tested, raffinose showed the maximum positive effect when compared to other sources such as sucrose, starch and fructose (Fig.1). On the other hand, glutamic acid (F) showed considerable effect and while other nitrogen sources (peptone, soy peptone and ammonium nitrate) showed no significant effect on rhAT yield (Fig.1). The yield of rhAT has been controlled by the required concentration of nitrogen in the medium. The optimum nitrogen level can simulate rhAT production, whereas high nitrogen level represses it. The supplementation of the nutrient medium with an appropriate vitamin mixture maximized the yield of rhAT. In the present study, vitamin mixture (L) also showed a significant effect (Fig.1) on rhAT yield. The addition of vitamin mixture in the growth medium had a optimistic impact on rhAT production. From the PB design analysis, it can be seen that raffinose, glutamic acid and vitamin mixture were screened to have a significant effect on rhAT production and the same were used for further experiments.

\section{Estimation of the optimal Concentrations and Interactive Effects of the important factors on $\operatorname{rhAT}$ production using CCD}

RSM was adapted to find out a proper direction by increasing or decreasing the concentrations of fermentation variables according to the results of PB design. Table 4 shows full factorial central composite design and their observed values of rhAT production. A regression model having $R^{2}$ value more than 0.9 was considered to be having a very high correlation. Hence, the present $R^{2}$ value reflected a very good fit between the observed and predicted responses of rhAT, and implied that the present model is consistent for rhAT production. The $F$-test also shows a high significance for the regression model. Each of the observed value is evaluated with a predicted value (Table. 4) and residuals with the residual variance indicates that none of the individual residues exceed twice the square root of the residual variance. All of these considerations specify a better adequacy of the regression model. Table 6 shows the ANOVA of the regression model with respect to rhAT. The goodness of fit of the model was examined by several criteria. A $P$ value of less than 0.0001 indicates that the model terms are significant. The fitness of the model was tested by the coefficient of determination $R^{2}$, which was found to be 0.9967 representing that the simple variation of $99.67 \%$ was attributed to the variables and only less than $0.33 \%$ of the total variance could not be explained by the model. 
Table 4: Full factorial central composite design and their observed responses for rhAT production.

\begin{tabular}{|c|c|c|c|c|c|c|}
\hline \multirow[b]{2}{*}{ 吾 } & \multicolumn{3}{|c|}{ Coded variables } & \multicolumn{3}{|c|}{ rhAT yield $(\mu \mathrm{g} / \mathrm{ml})$} \\
\hline & 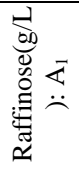 & 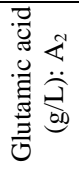 & 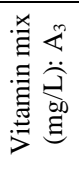 & 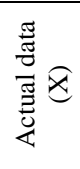 & 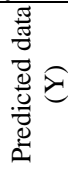 & 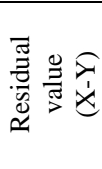 \\
\hline 1 & 10 & 6 & 60 & 27.35 & 27.51 & -0.16 \\
\hline 2 & 20 & 6 & 140 & 35.93 & 35.11 & 0.82 \\
\hline 3 & 15 & 4 & 20 & 27.09 & 26.93 & 0.16 \\
\hline 4 & 25 & 4 & 100 & 35.9 & 35.84 & 0.06 \\
\hline 5 & 20 & 6 & 60 & 36.8 & 36.62 & 0.18 \\
\hline 6 & 20 & 6 & 60 & 36.44 & 36.62 & -0.18 \\
\hline 7 & 20 & 6 & -20 & 27.11 & 27.25 & -0.14 \\
\hline 8 & 15 & 8 & 20 & 32.33 & 32.19 & 0.14 \\
\hline 9 & 15 & 8 & 100 & 35.5 & 35.34 & 0.16 \\
\hline 10 & 15 & 4 & 100 & 31.16 & 31.1 & 0.06 \\
\hline 11 & 20 & 10 & 60 & 37.3 & 37.44 & -0.14 \\
\hline 12 & 20 & 6 & 60 & 36.22 & 36.62 & -0.4 \\
\hline 13 & 20 & 6 & 60 & 36.39 & 36.62 & -0.23 \\
\hline 14 & 20 & 6 & 60 & 37.25 & 36.62 & 0.63 \\
\hline 15 & 25 & 8 & 100 & 38.97 & 38.93 & 0.04 \\
\hline 16 & 20 & 2 & 60 & 29.02 & 29.08 & -0.06 \\
\hline 17 & 25 & 4 & 20 & 30.29 & 30.25 & 0.04 \\
\hline 18 & 20 & 6 & 60 & 36.39 & 36.62 & -0.23 \\
\hline 19 & 30 & 6 & 60 & 34.38 & 34.42 & -0.04 \\
\hline 20 & 25 & 8 & 20 & 34.5 & 34.36 & 0.14 \\
\hline
\end{tabular}

Table 5: Analysis of variance for factorial model through PB Design.

\begin{tabular}{lccccc}
\hline \multicolumn{1}{c}{ Source } & Sum of Squares & $\mathbf{d}_{\mathbf{f}}$ & Mean Square & $\boldsymbol{F}$-value & Prob $>\boldsymbol{F}$ \\
\hline Model & 47.7 & 9 & 5.3 & 35.33 & 0.0278 \\
A & 12.4 & 1 & 12.4 & 82.69 & 0.0119 \\
B & 1.76 & 1 & 1.76 & 11.76 & 0.0756 \\
C & 0.48 & 1 & 0.48 & 3.2 & 0.2155 \\
D & 0.48 & 1 & 0.48 & 3.2 & 0.2155 \\
F & 18.25 & 1 & 18.25 & 121.69 & 0.0081 \\
G & 0.75 & 1 & 0.75 & 5 & 0.1548 \\
J & 2.08 & 1 & 2.08 & 13.89 & 0.0651 \\
K & 0.65 & 1 & 0.65 & 4.36 & 0.1722 \\
L & 10.83 & 1 & 10.83 & 72.2 & 0.0136 \\
Residual & 0.3 & 2 & 0.15 & & \\
Core total & 48 & 1 & & & \\
\hline
\end{tabular}

$\mathrm{d}_{\mathrm{f}}=$ Degrees of freedom

Table 6: Analysis of variance for regression model by central composite design.

\begin{tabular}{lccccc}
\hline \multicolumn{1}{c}{ Source } & Sum of squares & $\mathbf{d}_{\mathbf{f}}$ & Mean square & $\boldsymbol{F}$-Value & $\boldsymbol{P}$-value \\
\hline Model & 273.56 & 9 & 30.40 & 336.61 & 0.0001 \\
Lack of fit & 0.18 & 5 & 0.037 & 0.26 & 0.9192 \\
Error & 0.72 & 5 & 0.14 & & \\
Cor Total & 274.46 & 19 & & & \\
\hline $\mathrm{R}^{2}=0.9967, \quad$ Adj-R ${ }^{2}=0.9937, \mathrm{CV}=0.89 \%$ & & &
\end{tabular}

From the Table 7, it can be seen that the variables with higher effect were linear terms and squared terms of $A_{1}, A_{2}$ and $A_{3}$ followed by interaction between raffinose $\left(A_{1}\right)$ and vitamin mixture $\left(A_{3}\right)$. The higher significance of the linear terms and squared terms of $A_{1}, A_{2}$ and $A_{3}$ over corresponding interaction terms $\left(A_{1} A_{3}, A_{1} A_{2}\right.$, and $\left.A_{2} A_{3}\right)$ shows that the optimal values for rhAT production reclines within the experimental values chosen. From these observations, raffinose $\left(A_{1}\right)$, glutamic acid $\left(A_{2}\right)$ and vitamin mixture $\left(A_{3}\right)$ were shown to be significant.

The adjusted determination coefficient (adj $\left.R^{2}=0.9937\right)$ was also acceptable to confirm the significance of the present model. Finally, the lower value of coefficient of variation $(\mathrm{CV}=0.89 \%)$ shows that the experiments were exact and reliable.
The rhAT response model was analyzed as follows

$$
\begin{gathered}
\hat{\mathrm{Y}}=36.62+1.73 * \mathrm{~A}_{1}+2.09 * \mathrm{~A}_{2}+2.18 * \mathrm{~A}_{3}-0.29 * \mathrm{~A}_{1} \mathrm{~A}_{2}+0.36 * \mathrm{~A}_{1} \mathrm{~A}_{3}- \\
0.25 * \mathrm{~A}_{2} \mathrm{~A}_{3}-1.41 *\left(\mathrm{~A}_{1}\right)^{2}-0.84 *\left(\mathrm{~A}_{2}\right)^{2}-1.25 *\left(\mathrm{~A}_{3}\right)^{2} \ldots(5)
\end{gathered}
$$

The above response model can be converted into the un-coded unit where

$$
\begin{aligned}
& A_{1}=\left(Z_{1}-20\right) / 5 \ldots(6) \\
& A_{2}=\left(Z_{2}-6\right) / 2 \ldots(7) \\
& A_{3}=\left(Z_{3}-60\right) / 20 \ldots(8)
\end{aligned}
$$

In order to get a better understanding of significant medium supplements effect on rhAT production, the predicted model was presented as response surface graphs. The interaction between the effective medium components can be seen in the response surface (3D) and counter (2D) plots (Figs 2a-c).

The interaction between nutritional factors indicates that the change in level of one factor affects the level of remaining factor for a fixed level of rhAT yield. Fig $2 \mathrm{a}-\mathrm{c}$ shows the suitable

\begin{tabular}{|c|c|c|c|c|c|}
\hline 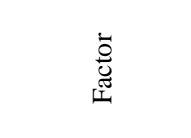 & 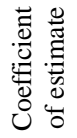 & 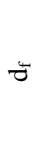 & 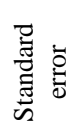 & $\underset{\frac{1}{3}}{\stackrel{0}{J}}$ & 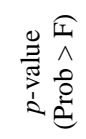 \\
\hline Intercept & 36.62 & 1 & 0.12 & & \\
\hline$A_{1}$-raffinose & 1.73 & 1 & 0.075 & 528.77 & 0.0001 \\
\hline $\mathrm{A}_{2 \text {-glutamicacid }}$ & 2.09 & 1 & 0.075 & 773.04 & 0.0001 \\
\hline $\mathrm{A}_{3}$-vitaminmix & 2.18 & 1 & 0.075 & 845.93 & 0.0001 \\
\hline $\mathrm{A}_{1} \mathrm{~A}_{2}$ & -0.29 & 1 & 0.11 & 7.32 & 0.0221 \\
\hline $\mathrm{A}_{1} \mathrm{~A}_{3}$ & 0.36 & 1 & 0.11 & 11.16 & 0.0075 \\
\hline $\mathrm{A}_{2} \mathrm{~A}_{3}$ & -0.25 & 1 & 0.11 & 5.76 & 0.0373 \\
\hline$\left(A_{1}\right)^{2}$ & -1.41 & 1 & 0.06 & 555.35 & 0.0001 \\
\hline$\left(A_{2}\right)^{2}$ & -0.84 & 1 & 0.06 & 195.77 & 0.0001 \\
\hline$\left(A_{3}\right)^{2}$ & -1.25 & 1 & 0.06 & 434.03 & 0.0001 \\
\hline
\end{tabular}
level of rafinose, glutamic acid and vitamin mixture to get utmost production of rhAT.

Table 7: Regression coefficients and their importance for response surface model.

A study has also been conducted to analyze the effect of the maximum and minimum principle of differential calculus on maximization of the equation (5) with respect to individual tested nutritional variables. The values of second order partial differential equations with respect to $A_{1}, A_{2}$ and $A_{3}$ obtained are $2.82 * A_{1},-1.68$ and -2.5 . The negative values of second order partial differential equations specify the absence of local maximum and applicability of rhAT maximization. First order partial differential model response equation 5 with respect $\mathrm{A}_{1}, \mathrm{~A}_{2}$ and $A_{3}$ are equated to zero and $A_{1}, A_{2}$ and $A_{3}$ values were solved with the maximum rhAT response.

$$
\begin{aligned}
& 1.73-2.82 * \mathrm{~A}_{1}-0.29 * \mathrm{~A}_{2}+0.36 * \mathrm{~A}_{3}=0 \\
& 2.09-0.29 * \mathrm{~A}_{1}-1.68 * \mathrm{~A}_{2}-0.25 * \mathrm{~A}_{3}=0 \\
& 2.18+0.36 * \mathrm{~A}_{1}-0.25 * \mathrm{~A}_{2}-2.5 * \mathrm{~A}_{3}=0
\end{aligned}
$$

The numerical solution to the above equations (9-11) were $A_{1}=$ 0.61953, $\mathrm{A}_{2}=1.00908$ and $\mathrm{A}_{3}=0.86028$. Uncoded values of $\mathrm{Z}_{1}=23.09765 \mathrm{~g} / \mathrm{L}, \mathrm{Z}_{2}=8.01816 \mathrm{~g} / \mathrm{L}$ and $\mathrm{Z}_{3}=77.2056 \mathrm{mg} / \mathrm{L}$ were estimated using equation 6-8. At these optimum concentrations, the maximum rhAT yield was estimated to be $38.97 \mu \mathrm{g} / \mathrm{ml}$. An improvement (2.3folds) of rhAT from $17.5 \mu \mathrm{g} / \mathrm{ml}$ (PBD) to38.97 $\mu \mathrm{g} / \mathrm{ml}$ was achieved after optimization using CCD. 

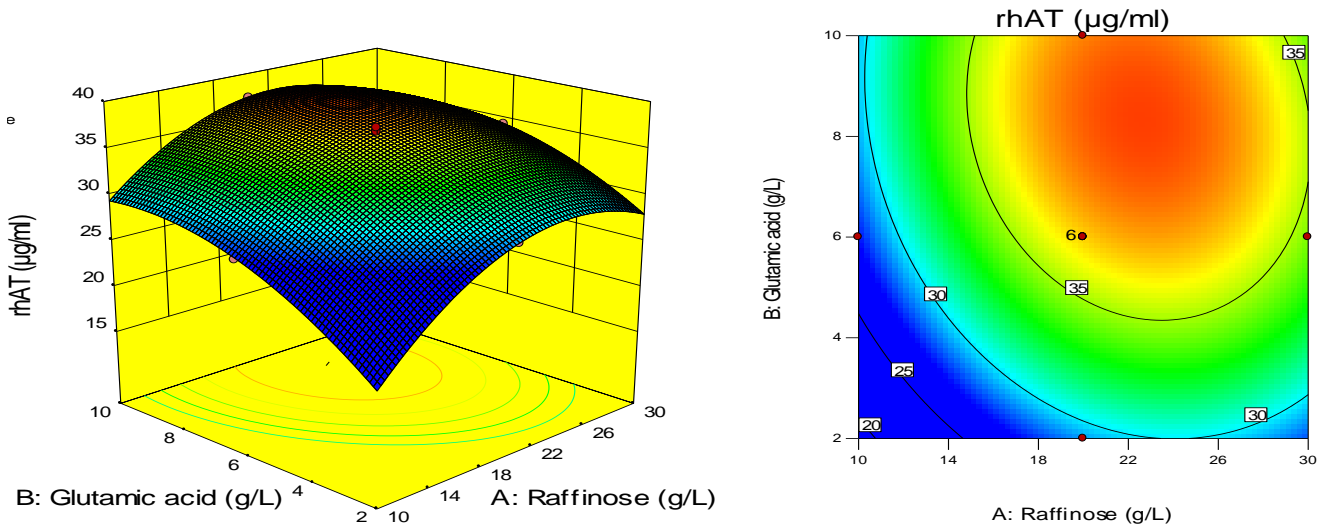

A
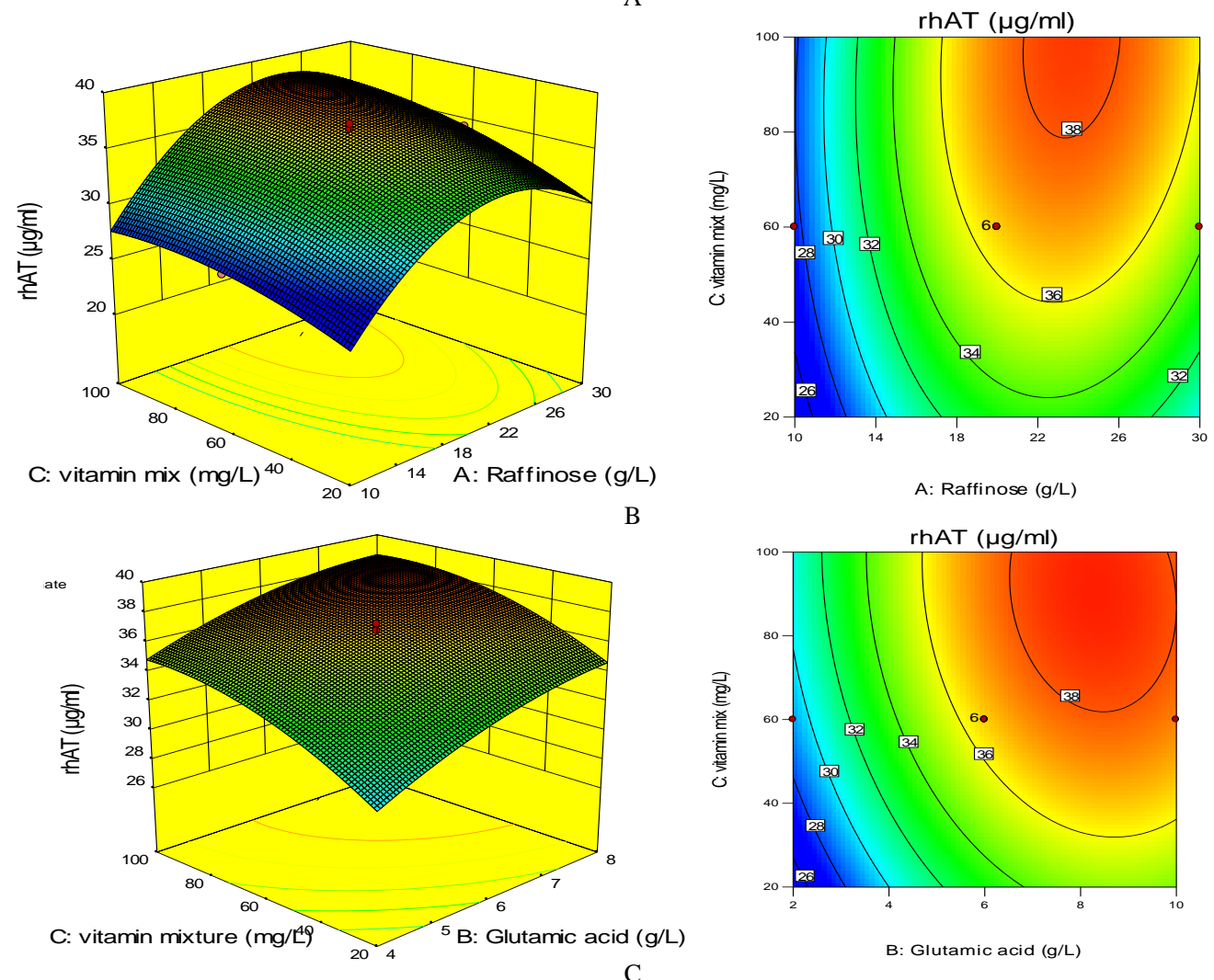

Fig. 2: Three dimension (3D) and two dimension (2D) response surface plots showing the effects of variables on rhAT production by $S$. cerevisiae. A) Interaction of raffinose $(\mathrm{g} / \mathrm{L})$ and glutamic acid $(\mathrm{g} / \mathrm{L})\left(\mathrm{A}_{1} \mathrm{~A}_{2}\right) ;(B)$ raffinose $(\mathrm{g} / \mathrm{L})$ and vitamin $\operatorname{mix}(\mathrm{mg} / \mathrm{L})\left(\mathrm{A}_{1} \mathrm{~A}_{3}\right) ;(\mathrm{C})$ glutamic acid and vitamin mix $\left(\mathrm{A}_{2} \mathrm{~A}_{3}\right)$.

\section{CONCLUSIONS}

The recombinant AT has gained enormous significance in the healthcare sector. Design expert analysis is the functional tool to optimize process variables for the production of recombinant proteins and provide valuable information on nutritional variable interactions.

In the present work, the effective variables on the rhAT production using PB design were screened. Three significant medium components screened from the PB design were raffinose, glutamic acid and vitamin mixture. The suitable concentrations of selected variables were optimized using CCD under response surface methodology.
The maximum predicted rhAT yield $(38.97 \mu \mathrm{g} / \mathrm{mL})$ from the CCD was achieved with raffinose $(23.09765 \mathrm{~g} / \mathrm{L})$, Glutamic acid $(8.01816 \mathrm{~g} / \mathrm{L})$ and vitamin mix $(77.2056 \mathrm{mg} / \mathrm{L})$. The proper use of media supplements can influence bioprocess economics at a large scale production of commercially value added therapeutic recombinant proteins.

\section{ACKNOWLEDGMENTS}

The authors are grateful to the Department of Biotechnology and management of $\mathrm{K} \mathrm{L} \mathrm{E} \mathrm{F} \mathrm{University} \mathrm{for}$ providing all the financial assistance and laboratory facilities during execution of the work. 


\section{REFERENCES}

Ahuja S; Ferreira G Moreira A. Application of PlackettBurman design and response surface methodology to achieve exponential growth for aggregated shipworm bacterium. Biotechnology and Bioengineering, 2004; 85: 666-67.

Bezerra M A; Santelli R E; Oliveira E P; Villar L S Escaleira L A. Response surface methodology (RSM) as a tool for optimization in analytical chemistry. Talanta, 2008; $76: 965-977$.

Bill R M. Yeast-a panacea for the structure-function analysis of membrane proteins? Current genetics. 2001;40: 157-171.

Box G E; Hunter J S , Hunter W G. Statistics for experimenters: design, innovation, and discovery. AMC, 2005; 1012.

Brereton R G. 2003. Chemometrics: data analysis for the laboratory and chemical plant; John Wiley \& Sons.

Damus P S; Hicks M Rosenberg R D. Anticoagulant action of heparin. Nature, 1973; 246: 355-7.

Demain A L Vaishnav P. Production of recombinant proteins by microbes and higher organisms. Biotechnology Advances, 2009; 27:297306.

De Stefano V; Za T; Rossi E; Vannucchi A M; Ruggeri M; Elli E; Micò C; Tieghi A; Cacciola R R Santoro C. Recurrent thrombosis in patients with polycythemia vera and essential thrombocythemia: incidence, risk factors, and effect of treatments. Haematologica, 2008; 93: 372-380.

Egeberg O. Inherited Antithrombin Deficiency Causing Thrombophilia. Thromb Diath Haemorrh, 1965;13:516-30.

Franzen L E; Svensson S Larm O. Structural studies on the carbohydrate portion of human antithrombin III. J Biol Chem, 1980; 255: 5090-3.

Freigassner M; Pichler $\mathrm{H}$ Glieder A. Tuning microbial hosts for membrane protein production. Microb Cell Fact, 2009;8:69.

Linhardt R J. 2003 Claude S. Hudson Award address in carbohydrate chemistry. Heparin: structure and activity. J Med Chem, 2003; 46: 2551-2564.

Mandenius C F, Brundin A. Bioprocess optimization using design-of-experiments methodology. Biotechnology Progress, 2008;24: 1191-1203.

Murano G; Williams L; Miller-Andersson M; Aronson D King C. Some properties of antithrombin-III and its concentration in human plasma. Thrombosis Research, 1980; 18: 259-262.
Petersen T; Dudek-Wojciechowska G; Sottrup-Jensen L Magnusson S. 1979. Primary structure of antithrombin III (heparin cofactor). Partial structure of antithrombin III (heparin cofactor). Partial homology between a1-antitrypsin and antithrombin III. The physiological inhibitors of blood coagulation and fibrinolysis. Elsevier Biomedical Press, Amsterdam. pp. 43-54.

Rao K J; Kim C-H Rhee S-K. Statistical optimization of medium for the production of recombinant hirudin from Saccharomyces cerevisiae using response surface methodology. Process Biochemistry, 2000; 35: 639-647.

Shojaosadati S A; Varedi Kolaei S M; Babaeipour V Farnoud A M. Recent advances in high cell density cultivation for production of recombinant protein. Iranian J Biotechnol, 2008; 6: 63-84.

Travis J Salvesen G S. Human plasma proteinase inhibitors. Annu Rev Biochem, 1983; 52:655-709.

Vemula S; Dedaniya A; Bandaru R; Mallu M R; Settaluri V S Ronda S R. Production of Recombinant Human Granulocyte-Colony Stimulating Factor in Escherichia coli Using Novel Media Supplements Through Integrated Statistical Optimization Designs. Int J Peptide Res Therap, 2015; 21: 1-14.

Vaidya R; Vyas P Chhatpar H. Statistical optimization of medium components for the production of chitinase by Alcaligenes xylosoxydans. Enzyme and Microbial Technology, 2003;33:92-96.

Weuster-Botz D. Experimental design for fermentation media development: statistical design or global random search? J Biosci Bioeng, 2000; 90: 473-483.

Wiedermann C J , Römisch J. The Anti-Inflammatory Actions of Antithrombin-A Review. Acta Medica Austriaca, 2002; 29: 89-92.

\section{How to cite this article:}

Maheswara Reddy Mallu, Sandeep Vemula, Srinivasa Reddy Ronda. Optimization of Fermentation Medium for the Production of Recombinant Antihrombin III from Saccharomyces cerevisiae through Statistical Experimental Designs. J App Pharm Sci, 2015; 5 (12): 014-020. 